\title{
Association Between Helicobacter pylori-Negative Peptic Ulcer Disease and Chronic Urticaria: A Retrospective Observational Study
}

\author{
Chengguo Zhang' \\ Yinbin $\mathrm{Wei}^{2}$ \\ 'Department of Dermatology, Hanchuan \\ People's Hospital, Hanchuan, 431600, \\ People's Republic of China; ${ }^{2}$ Department \\ of Infectious Diseases, Hanchuan People's \\ Hospital, Hanchuan, 431600, People's \\ Republic of China
}

Objective: The association between peptic ulcer disease (PUD) and chronic urticaria (CU) is rarely examined in individuals without Helicobacter pylori infection. The study aimed to investigate the association between Helicobacter pylori-negative PUD and CU.

Methods: Patients without Helicobacter pylori infection were retrospectively enrolled from those who visited the clinic or were admitted to the ward of the dermatological department with recent gastroscopy and Helicobacter pylori testing in a tertiary hospital between 2015 and 2019. After categorizing them as patients with and without PUD, we used propensity score matching to identify a cohort of PUD and a control cohort at a ratio of 1:2. CU was determined by examining medical records of the two cohorts, and logistic regression analyses were used to evaluate the association between PUD and CU with or without adjusting for covariates.

Results: We included 40 patients with PUD as the PUD cohort and 80 patients without PUD as the control cohort, between which there were no significant differences in patient characteristics, including age, sex, and several comorbidities $(\mathrm{P}$ all $>0.05)$. Among the PUD cohort, $25.00 \%(10 / 40)$ of them were with $\mathrm{CU}$, which was significantly higher than that in the control cohort $8.75 \%(7 / 80, \mathrm{P}=0.016)$. Results of logistic regression analyses showed PUD was significantly associated with increased risk of CU (odds ratio (OR) 3.48, 95\% confidence interval (CI) 1.21-9.99, $\mathrm{P}=0.021$ ), which was consistent with that after adjusted for potential confounding factors (OR 3.77, 95\% CI 1.24-11.45, P =0.019).

Conclusion: Helicobacter pylori-negative PUD is associated with increased risk of CU.

Keywords: chronic urticaria, peptic ulcer, risk factors, Helicobacter pylori

\section{Introduction}

Chronic urticaria (CU) is defined by the presence of recurrent urticaria (which is also called hives or wheals), angioedema, or both, for a period of six weeks or longer. ${ }^{1}$ It is estimated that up to $1 \%$ of the general population in the United States had $\mathrm{CU}^{2}$, and similar prevalence was reported in other countries. ${ }^{3,4}$ Although $\mathrm{CU}$ is usually self-limited for most patients, the quality of life can be significantly impaired by active CU due to the debilitating symptoms. ${ }^{5,6}$ Real-world evidence indicated that $\mathrm{CU}$ has considerable humanistic and economic impacts, and $\mathrm{CU}$ treatment consumes significant health-care resources and costs. ${ }^{7}$

Although some hypotheses have been developed, including the autoimmune theory, ${ }^{8}$ theories involving histamine-releasing factors, ${ }^{9,10}$ and the cellular defects theory, ${ }^{11,12}$ the pathogenesis of CU has not been fully established yet. However, CU
Correspondence: Yinbin Wei

Department of Infectious Diseases, Hanchuan People's Hospital, No. I Renmin

Avenue, Hanchuan, 431600, People's

Republic of China

Email weiyinbinI I83840@I63.com 
is observed to be associated with some conditions, including various atopic and autoimmune disorders. For example, a large cohort study found there were strong associations of CU with allergic diseases including food allergy, allergic rhinitis, chronic rhinosinusitis, atopic dermatitis, and asthma. ${ }^{13}$ Several population-based studies found various autoimmune conditions, including thyroid disorders, celiac disease, Sjögren syndrome, systemic lupus erythematosus, rheumatoid arthritis, and type 1 diabetes mellitus, were more prevalent among patients with CU. ${ }^{8,14-17}$ Obviously, identifying CU associated conditions will be helpful for early diagnosis and treatment of $\mathrm{CU}$ in order to reduce its negative impact on quality of life.

Peptic ulcer disease (PUD) is a condition with the presence of defects in the gastric and/or duodenal wall that extend through the muscularis mucosa into the deeper layers of the wall, which remains an important cause of morbidity and health-care costs. ${ }^{18} \mathrm{~A}$ few studies had investigated the association between PUD and CU, which suggested PUD was a risk factor of CU. ${ }^{19,20}$ Helicobacter pylori (HP) infection is a main cause of PUD (which accounts for about $50 \%$ of the PUD cases) ${ }^{21}$, and several studies have suggested an association between HP infection and $\mathrm{CU},{ }^{22,23}$ but it remains unknown whether the association between PUD and CU is independent of HP infection. The current study aimed to investigate the association between HP-negative PUD and CU.

\section{Methods}

\section{Study Participants}

We retrospectively identified a cohort of PUD patients without HP infection, and a control cohort without PUD and HP infection as the study participants (Figure 1). In detail, we examined the hospital data of the Hanchuan People's Hospital between 2015 and 2019 according to the below inclusion criteria: (1) patients who visited the

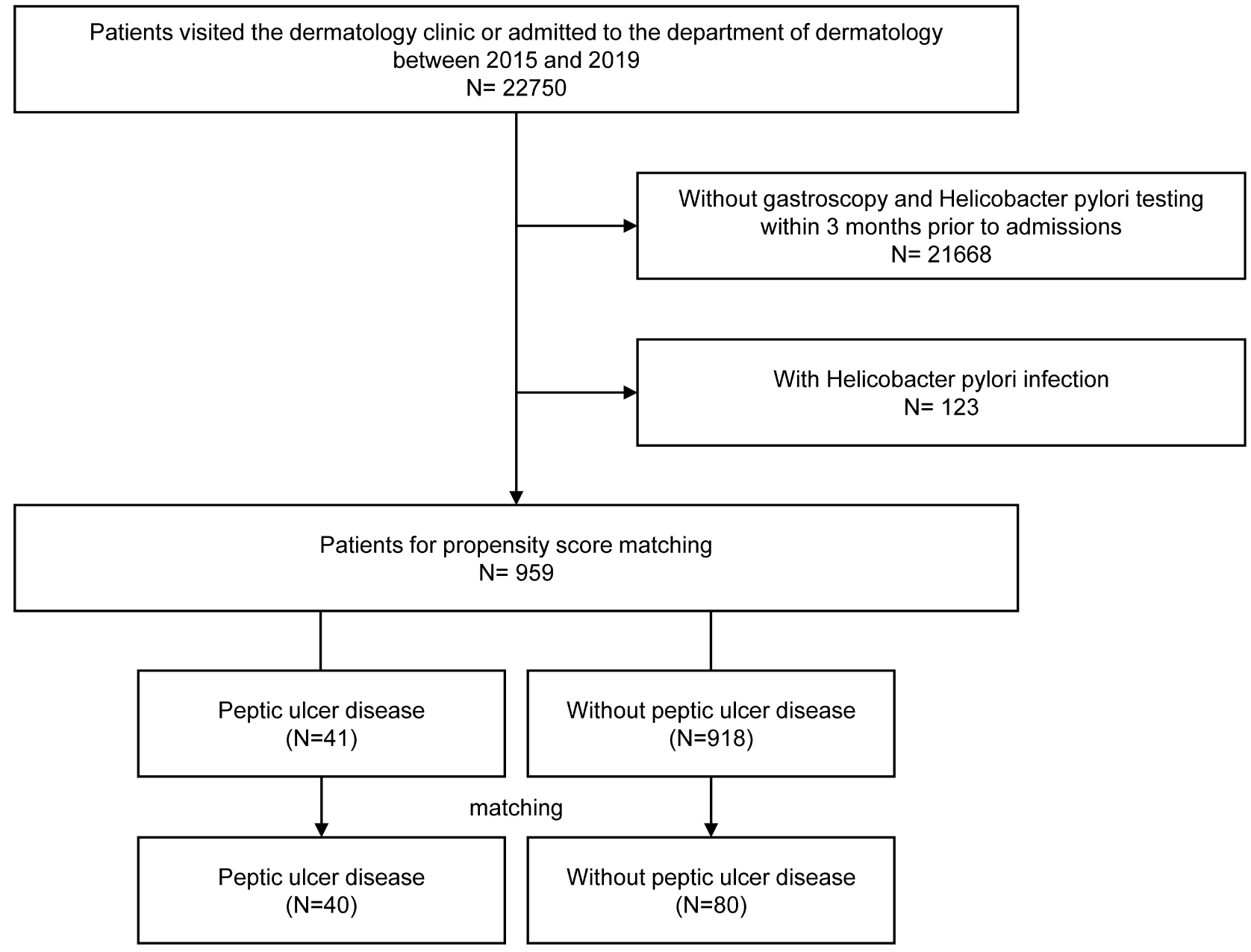

Figure I Inclusion of the study participants. 
dermatology clinic or who were admitted to the department of dermatology of Hanchuan People's Hospital between 2015 and 2019; (2) patients who underwent gastroscopy and HP testing (regardless of indications) within 3 months prior to the visits or the admissions; (3) patients without HP infection (identified by the results of HP testing). After excluding patients who were aged $<18$ years, we performed a propensity score matching among the eligible patients at a ratio of 1:2 to obtain a cohort of PUD (identified as below stated) and a cohort without PUD according to the covariates stated below. The study was approved by the ethical committee of Hanchuan People's Hospital and informed consent was waived because the study was retrospective and only anonymous data were used. This study was conducted in accordance with the Declaration of Helsinki.

\section{Exposure}

PUD was the exposure of the study, which was determined by the diagnosis records on the examination report of gastroscopy made by the clinicians who performed the gastroscopy. In the Hanchuan People's Hospital, gastroscopy and HP testing are mainly ordered and performed by the clinicians from the Department of Gastroenterology. The indications of gastroscopy vary between patients, which are mainly for diagnosis of esophageal and gastroduodenal disease and sometimes for treatment of some conditions (such as upper gastrointestinal bleeding), but it is also possible to perform gastroscopy as routine check-up when requested by the patients. HP testing is commonly ordered together with gastroscopy, but mainly examined by the HP $\mathrm{C} 13$ urea breath test instead of by biopsy-based test.

\section{Outcome}

We examined the medical data of the visit of the dermatology clinic and medical data on the hospitalization in the department of dermatology to determine the study outcome CU. During the study period (2015-2019), the diagnosis of CU in daily practice in the Hanchuan People's Hospital was based on the Chinese guidelines for the diagnosis and treatment of urticaria (version 2014). ${ }^{24} \mathrm{In}$ brief, $\mathrm{CU}$ was diagnosed for patients with recurrent urticaria with or without angioedema for at least six weeks after excluding physical urticaria.

\section{Covariates}

By reviewing the medical data of the visit of the dermatology clinic and medical data on the hospitalization in the department of dermatology, we identified the below covariates: age, sex, and comorbidities including allergic rhinitis, asthma, other chronic lung diseases, coronary heart disease, liver disease, renal disease, thyroid disease, diabetes, rheumatic disease, malignant tumor, atopic dermatitis, and family history of chronic urticaria.

\section{Statistical Analysis}

We expressed continuous data as mean \pm standard deviation, and categorical data as frequency and percentage. Comparisons between two cohorts were examined by an independent $t$-test for continuous, and by chi-squared test (or Fisher's exact test) for categorical data. Univariable logistic regression analyses were used to examine covariates associated with $\mathrm{CU}$, and multivariable logistic regression analyses were used to evaluate the association between PUD and CU after adjusting for those covariates with a $\mathrm{P}$ value $<0.3$ in the univariable logistic regression analyses. A P value less than 0.05 was considered statistically significant. The SPSS software (version 22.0) was used for the analyses.

\section{Results}

\section{Characteristics of the Study Participants}

We included 40 patients with PUD as the PUD cohort and 80 patients without PUD as the control cohort (Figure 1). The mean age of the PUD cohort was $53.40 \pm 18.78$ years, which was similar in the control cohort $(51.21 \pm 20.36$ years, $\mathrm{P}=0.570$ ). There were no significant differences in other patient characteristics, including age, sex, and several comorbidities (P all $>0.05$, Table 1 ).

\section{Covariates Associated with CU}

According to results of univariable analysis (Table 2), female sex, comorbid allergic rhinitis, asthma, renal disease, diabetes, rheumatic disease, malignant tumor, and atopic dermatitis appeared to be associated with increased risk of $\mathrm{CU}$, but all the associations were not statistically significant $(\mathrm{P}$ all $>0.05)$.

\section{Association Between PUD and CU}

Among the PUD cohort 25.00\% (10/40) of them were with $\mathrm{CU}$, which was significantly higher than that in the control cohort $8.75 \%(7 / 80, P=0.016)$. As shown in Table 3, results of univariable logistic regression analyses showed PUD was significantly associated with increased risk of CU (odds ratio (OR) 3.48, 95\% confidence interval (CI) 
Table I Characteristics of the Study Participants

\begin{tabular}{|l|l|l|l|l|}
\hline & $\begin{array}{l}\text { Peptic Ulcer Disease } \\
(\mathbf{n}=\mathbf{4 0})\end{array}$ & Control (n = 80) & $\begin{array}{l}\text { Standardize Difference } \\
\text { (95\% Confidence Interval) }\end{array}$ & P value \\
\hline Age (years) & $53.40 \pm 18.78$ & $51.21 \pm 20.36$ & $0.11(-0.27-0.49)$ & 0.570 \\
\hline Sex & & & $0.15(-0.23-0.53)$ & 0.438 \\
$\quad$ Male & $21(52.50 \%)$ & $36(45.00 \%)$ & & \\
$\quad$ Female & $19(47.50 \%)$ & $44(55.00 \%)$ & & 0.610 \\
\hline Allergic rhinitis & $6(15.00 \%)$ & $15(18.75 \%)$ & $0.10(-0.28-0.48)$ & 0.115 \\
Asthma & $5(12.50 \%)$ & $3(3.75 \%)$ & $0.32(-0.06-0.7 I)$ & 0.559 \\
Other chronic lung diseases & $12(30.00 \%)$ & $20(25.00 \%)$ & $0.11(-0.27-0.49)$ & 0.333 \\
Coronary heart disease & $6(15.00 \%)$ & $18(22.50 \%)$ & $0.19(-0.19-0.57)$ & 0.479 \\
Liver disease & $4(10.00 \%)$ & $5(6.25 \%)$ & $0.14(-0.24-0.52)$ & 0.053 \\
Renal disease & $7(17.50 \%)$ & $5(6.25 \%)$ & $0.35(-0.03-0.74)$ & 0.600 \\
Thyroid disease & $2(5.00 \%)$ & $2(2.50 \%)$ & $0.13(-0.25-0.5 I)$ & 0.242 \\
Diabetes & $3(7.50 \%)$ & $12(15.00 \%)$ & $0.24(-0.14-0.62)$ & 1.000 \\
Rheumatic disease & $1(2.50 \%)$ & $2(2.50 \%)$ & $0.00(-0.38-0.38)$ & 1.000 \\
Malignant tumor & $1(2.50 \%)$ & $1(1.25 \%)$ & $0.09(-0.29-0.47)$ & 0.257 \\
Atopic dermatitis & $2(5.00 \%)$ & $1(1.25 \%)$ & $0.22(-0.16-0.60)$ & 0.664 \\
Family history of chronic urticaria & $1(2.50 \%)$ & $4(5.00 \%)$ & $0.13(-0.25-0.5 \mathrm{I})$ & 0.016 \\
Chronic urticaria & $10(25.00 \%)$ & $7(8.75 \%)$ & $0.44(0.06-0.83)$ & \\
\hline
\end{tabular}

1.21-9.99, $\mathrm{P}=0.021$ ), which was consistent with that after adjusted for age, sex, coronary heart disease, and malignant tumor (OR 3.77, 95\% CI 1.24-11.45, $\mathrm{P}=0.019$ ).

\section{Discussion}

The current study investigated the association between PUD and $\mathrm{CU}$ in patients without HP infection, and the main finding is that PUD is associated with increased risk of $\mathrm{CU}$, which is independent of HP infection. This finding provides knowledge about the association between PUD and $\mathrm{CU}$ in HP negative population which was rarely investigated before, and suggests to consider PUD and CU as associated conditions in practice and therefore to enhance the diagnosis and management of these two conditions.

The association between HP infection and CU has been investigated in various studies. In the meta-analysis by $\mathrm{Gu}$ et $\mathrm{al}^{22}$ that included 16 studies involving $965 \mathrm{CU}$ cases and 1235 controls, HP infection was found to be significantly but weakly associated with $\mathrm{CU}$, while a more recent meta-analysis by Kim et $\mathrm{al}^{25}$ found that resolution of CU was not associated with successful eradication of HP infection. However, evidence about the association between PUD and CU is very limited. A large populationbased study found patients with $\mathrm{CU}$ had significantly higher prevalence of PUD (standardized prevalence ratio 1.76) compared to the general population. ${ }^{19}$ Since HP infection is common (but not always, about $50 \%)^{21}$ in PUD patients, it is interesting to investigate whether the association between PUD and CU is independent of HP infection. Zheleznov et $\mathrm{a}^{20}$ prospectively enrolled $36 \mathrm{CU}$ patients and found patients who succeeded in healing the erosions showed significantly better improvement of urticarial symptoms when compared to those who did not succeed, which was independent of the presence of HP infection. Chen et $\mathrm{al}^{26}$ retrospectively enrolled three cohorts, namely PUD patients with HP infection, PUD patients without HP infection, and a cohort without PUD and HP infection, and found PUD is associated with CU independent of HP infection. These findings are consistent with the finding of our study, although we used a different study design that only patients without HP infection were studied. Compared to the study by Chen et al, ${ }^{26}$ our study population was from a more recent period and PUD was identified based on examination reports of gastroscopy, which could be the novelty of our study. Our study also investigated the patient characteristics associated with $\mathrm{CU}$, and we found some characteristics, such as female sex, comorbid allergic diseases, or rheumatic disease, appeared to be associated with increased risk of $\mathrm{CU}$, which were consistent with other studies, ${ }^{19,27,28}$ although in our study the associations were not statistically significant due to a small sample size. 
Table 2 Univariable Analysis of Covariates Associated with Chronic Urticaria

\begin{tabular}{|c|c|c|c|}
\hline & $\begin{array}{l}\text { Odds } \\
\text { Ratio }\end{array}$ & $95 \% \mathrm{Cl}$ & $P$ value \\
\hline Age (years) & 0.98 & $0.95-1.01$ & 0.165 \\
\hline \multicolumn{4}{|l|}{ Sex } \\
\hline Male & 1.0 & & \\
\hline Female & 1.80 & $0.62-5.23$ & $0.28 \mathrm{I}$ \\
\hline \multicolumn{4}{|l|}{ Allergic rhinitis } \\
\hline No & 1.0 & & \\
\hline Yes & 1.56 & $0.45-5.35$ & 0.483 \\
\hline \multicolumn{4}{|l|}{ Asthma } \\
\hline No & 1.0 & & \\
\hline Yes & 2.16 & $0.40-11.68$ & 0.373 \\
\hline \multicolumn{4}{|l|}{ Other chronic lung diseases } \\
\hline No & 1.0 & & \\
\hline Yes & 0.82 & $0.25-2.74$ & 0.753 \\
\hline \multicolumn{4}{|l|}{ Coronary heart disease } \\
\hline No & 1.0 & & \\
\hline Yes & 0.22 & $0.03-1.73$ & 0.149 \\
\hline \multicolumn{4}{|l|}{ Liver disease } \\
\hline No & 1.0 & & \\
\hline Yes & 0.74 & $0.09-6.34$ & 0.785 \\
\hline \multicolumn{4}{|l|}{ Renal disease } \\
\hline No & 1.0 & & \\
\hline Yes & 1.24 & $0.25-6.22$ & 0.794 \\
\hline \multicolumn{4}{|l|}{ Thyroid disease } \\
\hline No & 1.0 & & \\
\hline Yes & 0.00 & $0.00-\operatorname{Inf}$ & 0.990 \\
\hline \multicolumn{4}{|l|}{ Diabetes } \\
\hline No & 1.0 & & \\
\hline Yes & 1.62 & $0.4 I-6.49$ & 0.492 \\
\hline \multicolumn{4}{|l|}{ Rheumatic disease } \\
\hline No & 1.0 & & \\
\hline Yes & 3.16 & $0.27-36.86$ & 0.359 \\
\hline \multicolumn{4}{|l|}{ Malignant tumor } \\
\hline No & 1.0 & & \\
\hline Yes & 6.37 & $0.38-107.11$ & 0.198 \\
\hline \multicolumn{4}{|l|}{ Atopic dermatitis } \\
\hline No & 1.0 & & \\
\hline Yes & 3.16 & $0.27-36.86$ & 0.359 \\
\hline \multicolumn{4}{|l|}{$\begin{array}{l}\text { Family history of chronic } \\
\text { urticaria }\end{array}$} \\
\hline No & 1.0 & & \\
\hline Yes & 0.00 & $0.00-\operatorname{lnf}$ & 0.993 \\
\hline
\end{tabular}

Abbreviation: $\mathrm{Cl}$, confidence interval.
Table 3 Multivariable Analysis Between Peptic Ulcer Disease and Chronic Urticaria

\begin{tabular}{|l|l|l|l|}
\hline & Odds Ratio & $\mathbf{9 5 \%} \mathbf{~ C l}$ & P value \\
\hline $\begin{array}{l}\text { Crude model } \\
\text { Control } \\
\text { Peptic ulcer disease }\end{array}$ & 1.0 & & \\
\hline $\begin{array}{l}\text { Adjusted model* } \\
\text { Control } \\
\text { Peptic ulcer disease }\end{array}$ & 1.0 & $1.21-9.99$ & 0.021 \\
\hline
\end{tabular}

Note: *Adjusted for age, sex, coronary heart disease, and malignant tumor. Abbreviation: $\mathrm{Cl}$, confidence interval.

There could be biological plausibility for the link between PUD and CU. According to the autoimmune theory of $\mathrm{CU}, \mathrm{CU}$ may be an autoimmune disorder with autoantibodies or other histamine-releasing factor, among which an increased level of blood histamine is prevalent, ${ }^{29,30}$ while the role of histamine in the pathogenesis PUD has been established. ${ }^{31,32}$ In addition, a low mucosal diamine oxidase activity observed in PUD patients could also be a mechanism of increasing risk CU. ${ }^{33,34}$ Obviously, more evidences are needed to explain the association between PUD and CU at the absence of HP infection. If the biological mechanisms behind the association are identified and a casual association is established, it will be very promising by benefiting the management of $\mathrm{CU}$ from the management of PUD.

There are some strengths in our study. First, we used propensity score matching to obtain a PUD cohort and a control cohort, which made there was no significant difference in other patient characteristics between the two cohorts. Second, all the study participants were outpatients or inpatients of the department of dermatology, which made it less likely that CU was misdiagnosed. Third, all the PUD were diagnosed based on gastroscopy, which increased the validity of the study exposure. However, there are some limitations in our study. First, due to the retrospective study design, we only included patients who visited the dermatology clinic or who were admitted to the department of dermatology with recent examinations of PUD and HP infection. This makes the sample size of our study very limited. Further studies should consider using a prospective study design and perform screen of PUD and HP infection among the study participants. Second, although we enrolled propensity score matched cohorts, our study is still at risk of residual confounding. This is because we only studied several covariates, without including information such as medications use (eg, proton 
pump inhibitors, $\mathrm{H}_{2}$-receptor antagonists, non-steroidal antiinflammatory drugs). Third, due to data limitation and the small sample size, the covariates were not identified based on strict criteria and they were presented at a rather general level. Last but not least, we did not investigate whether the successful treatment of PUD will benefit CU in patients without HP infection. Further studies are warranted for this investigation.

\section{Conclusions}

In summary, by using routine collected medical data from daily practice, we demonstrated that in patients without HP infection, PUD is associated with increased risk of CU. This suggests to consider PUD and CU as associated conditions in practice and therefore to enhance the diagnosis and management of these two conditions. However, more studies are needed to confirm our findings given the limitations of our study, and it is also necessary to explore the underlying mechanisms, as well as the potential benefit of PUD treatment on CU.

\section{Funding}

There is no funding to report.

\section{Disclosure}

The authors report no conflicts of interest in this work.

\section{References}

1. Zuberbier T, Aberer W, Asero R, et al. The EAACI/GA(2)LEN/EDF/ WAO guideline for the definition, classification, diagnosis and management of urticaria. Allergy. 2018;73:1393-1414. doi:10.1111/all.13397

2. Greaves M. Chronic urticaria. $J$ Allergy Clin Immunol. 2000;105:664-672. doi:10.1067/mai.2000.105706

3. Gaig P, Olona M, Munoz Lejarazu D, et al. Epidemiology of urticaria in Spain. J Investig Allergol Clin Immunol. 2004;14:214-220.

4. Lapi F, Cassano N, Pegoraro V, et al. Epidemiology of chronic spontaneous urticaria: results from a nationwide, population-based study in Italy. Br J Dermatol. 2016;174:996-1004. doi:10.1111/bjd.14470

5. Dias GA, Pires GV, Valle SO, et al. Impact of chronic urticaria on the quality of life of patients followed up at a university hospital. An Bras Dermatol. 2016;91:754-759. doi:10.1590/abd1806-4841.20165071

6. Weldon DR. Quality of life in patients with urticaria. Allergy Asthma Proc. 2006;27:96-99.

7. Maurer M, Abuzakouk M, Berard F, et al. The burden of chronic spontaneous urticaria is substantial: real-world evidence from ASSURE-CSU. Allergy. 2017;72:2005-2016. doi:10.1111/all.13209

8. Confino-Cohen R, Chodick G, Shalev V, Leshno M, Kimhi O, Goldberg A. Chronic urticaria and autoimmunity: associations found in a large population study. $J$ Allergy Clin Immunol. 2012;129:1307-1313. doi:10.1016/j.jaci.2012.01.043

9. Asero R, Tedeschi A, Riboldi P, Cugno M. Plasma of patients with chronic urticaria shows signs of thrombin generation, and its intradermal injection causes wheal-and-flare reactions much more frequently than autologous serum. J Allergy Clin Immunol. 2006;117:1113-1117. doi:10.1016/j.jaci.2005.12.1343
10. Asero R, Tedeschi A, Coppola R, et al. Activation of the tissue factor pathway of blood coagulation in patients with chronic urticaria. J Allergy Clin Immunol. 2007;119:705-710. doi:10.1016/j.jaci.2006.08.043

11. Jacques P, Lavoie A, Bedard PM, Brunet C, Hebert J. Chronic idiopathic urticaria: profiles of skin mast cell histamine release during active disease and remission. $J$ Allergy Clin Immunol. 1992;89:1139-1143. doi:10.1016/0091-6749(92)90297-F

12. Cohen RW, Rosenstreich DL. Discrimination between urticaria-prone and other allergic patients by intradermal skin testing with codeine. $J$ Allergy Clin Immunol. 1986;77:802-807. doi:10.1016/00916749(86)90377-5

13. Rosman Y, Hershko AY, Meir-Shafrir K, et al. Characterization of chronic urticaria and associated conditions in a large population of adolescents. J Am Acad Dermatol. 2019;81:129-135. doi:10.1016/j. jaad.2019.02.034

14. Kozel MM, Bossuyt PM, Mekkes JR, Bos JD. Laboratory tests and identified diagnoses in patients with physical and chronic urticaria and angioedema: a systematic review. $J$ Am Acad Dermatol. 2003;48:409-416. doi:10.1067/mjd.2003.142

15. Leznoff A, Sussman GL. Syndrome of idiopathic chronic urticaria and angioedema with thyroid autoimmunity: a study of 90 patients. J Allergy Clin Immunol. 1989;84:66-71. doi:10.1016/0091-6749(89) 90180-2

16. Dreskin SC, Andrews KY. The thyroid and urticaria. Curr Opin Allergy Clin Immunol. 2005;5:408-412. doi:10.1097/01. all.0000182546.83465.5a

17. Caffarelli C, Cuomo B, Cardinale F, et al. Aetiological factors associated with chronic urticaria in children: a systematic review. Acta Derm Venereol. 2013;93:268-272. doi:10.2340/00015555-1511

18. Peery AF, Dellon ES, Lund J, et al. Burden of gastrointestinal disease in the United States: 2012 update. Gastroenterology. 2012;143:11791187 e1173. doi:10.1053/j.gastro.2012.08.002

19. Chu CY, Cho YT, Jiang JH, Lin EI, Tang CH. Epidemiology and comorbidities of patients with chronic urticaria in Taiwan: a nationwide population-based study. $J$ Dermatol Sci. 2017;88:192-198. doi:10.1016/j.jdermsci.2017.07.006

20. Zheleznov S, Urzhumtseva G, Petrova N, et al. Gastritis can cause and trigger chronic spontaneous urticaria independent of the presence of Helicobacter pylori. Int Arch Allergy Immunol. 2018;175:246-251. doi: $10.1159 / 000487669$

21. Kurata JH, Nogawa AN. Meta-analysis of risk factors for peptic ulcer. Nonsteroidal antiinflammatory drugs, Helicobacter pylori, and smoking. J Clin Gastroenterol. 1997;24:2-17. doi:10.1097/ 00004836-199701000-00002

22. Gu H, Li L, Gu M, Zhang G. Association between Helicobacter pylori infection and chronic urticaria: a meta-analysis. Gastroenterol Res Pract. 2015;2015:486974. doi:10.1155/2015/ 486974

23. Campanati A, Gesuita R, Giannoni M, et al. Role of small intestinal bacterial overgrowth and Helicobacter pylori infection in chronic spontaneous urticaria: a prospective analysis. Acta Derm Venereol. 2013;93:161-164. doi:10.2340/00015555-1373

24. Immunology Group DB, Chinese Medical Association. [Chinese guidelines for the diagnosis and treatment of urticaria version 2014]. Chin J Dermatol. 2014;47:514-516. Chinese.

25. Kim HJ, Kim YJ, Lee HJ, et al. Systematic review and meta-analysis: effect of Helicobacter pylori eradication on chronic spontaneous urticaria. Helicobacter. 2019;24:e12661. doi:10.1111/hel.12661

26. Chen CM, Huang WT, Chang LJ, Hsu CC, Hsu YH. Peptic ulcer disease is associated with increased risk of chronic urticaria independent of Helicobacter pylori infection: a population-based cohort study. Am J Clin Dermatol. 2021;22:129-137. doi:10.1007/s40257020-00561-9

27. Cassano N, Colombo D, Bellia G, Zagni E, Vena GA. Gender-related differences in chronic urticaria. G Ital Dermatol Venereol. 2016;151:544-552. 
28. Bansal CJ, Bansal AS. Stress, pseudoallergens, autoimmunity, infection and inflammation in chronic spontaneous urticaria. Allergy Asthma Clin Immunol. 2019;15:56. doi:10.1186/s13223-019-0372-z

29. Grattan CE, Wallington TB, Warin RP, Kennedy CT, Bradfield JW. A serological mediator in chronic idiopathic urticaria - a clinical, immunological and histological evaluation. Br J Dermatol. 1986;114:583-590. doi:10.1111/j.1365-2133.1986.tb04065.x

30. Fagiolo U, Kricek F, Ruf C, Peserico A, Amadori A, Cancian M. Effects of complement inactivation and $\mathrm{IgG}$ depletion on skin reactivity to autologous serum in chronic idiopathic urticaria. J Allergy Clin Immunol. 2000;106:567-572. doi:10.1067/mai.2000.108913

31. Barth H, Troidl H, Lorenz W, Rohde H, Glass R. Histamine and peptic ulcer disease: histamine methyltransferase activity in gastric mucosa of control subjects and duodenal ulcer patients before and after surgical treatment. Agents Actions. 1977;7:75-79. doi:10.1007/BF01964884
32. Hetenyi G. The role of histamine in the production of peptic ulcer. Gastroenterologia. 1956;86:489-493. doi:10.1159/ 000200608

33. Lessof MH, Gant V, Hinuma K, Murphy GM, Dowling RH. Recurrent urticaria and reduced diamine oxidase activity. Clin Exp Allergy. 1990;20:373-376. doi:10.1111/j.1365-2222.1990. tb02796.x

34. Kusche J, Lorenz W, Stahlknecht CD, et al. Diamine oxidase activity in gastric and duodenal mucosa of man and other mammals with special reference to the pyloric junction. Agents Actions. 1978;8:366-371. doi:10.1007/BF01968616

\section{Publish your work in this journal}

Clinical, Cosmetic and Investigational Dermatology is an international, peer-reviewed, open access, online journal that focuses on the latest clinical and experimental research in all aspects of skin disease and cosmetic interventions. This journal is indexed on CAS.
The manuscript management system is completely online and includes a very quick and fair peer-review system, which is all easy to use. Visit http://www.dovepress.com/testimonials.php to read real quotes from published authors. 